Pacific Journal of Mathematics

THE ANGULAR DERIVATIVE OF AN OPERATOR-VALUED 


\section{THE ANGULAR DERIVATIVE OF AN OPERATOR-VALUED ANALYTIC FUNCTION}

\section{KY FAN}

The classical theorem on the angular derivative of an analytic function on the half-plane $\operatorname{Re} z>0$ is extended to operator-valued analytic functions.

1. Let $\Pi$ denote the open half-plane

$$
\Pi=\{z \in \mathbf{C}: \operatorname{Re} z>0\} .
$$

For a positive number $k$, let $\Sigma_{k}$ denote the set

$$
\Sigma_{k}=\{z \in \mathbf{C}:|\operatorname{Im} z|<k \operatorname{Re} z\} .
$$

The following theorem in complex analysis is well-known:

Let $f$ be a function analytic on $\Pi$ such that $f(\Pi) \subset \Pi$. If

$$
a=\inf _{z \in \Pi} \frac{\operatorname{Re} f(z)}{\operatorname{Re} z}
$$

then for any $k>0$, we have

$$
\lim _{\substack{z \rightarrow \infty \\ z \in \Sigma_{k}}} \frac{f(z)}{z}=\lim _{\substack{z \rightarrow \infty \\ z \in \Sigma_{k}}} \frac{\operatorname{Re} f(z)}{\operatorname{Re} z}=\lim _{\substack{z \rightarrow \infty \\ z \in \Sigma_{k}}} f^{\prime}(z)=a .
$$

The limit $\lim _{z \rightarrow \infty, z \in \Sigma_{k}} f^{\prime}(z)$ is usually called the angular derivative of $f$ at $\infty$. The above classical theorem is the work of several mathematicians: Julia, Nevanlinna, Wolff, Carathéodory, Landau, Valiron. For the original sources, the reader is referred to [2, p. 216] and [5, p.108]. The purpose of the present paper is to extend this classical theorem to operator-valued analytic functions [3, pp. 92-94].

2. Throughout this paper, $\mathscr{H}$ denotes a complex Hilbert space. By an operator we always mean a bounded linear operator on $\mathscr{H}$. The identity operator is denoted by $I$. For an operator $A$ on $\mathscr{H}$, the adjoint of $A$ is denoted by $A^{*}$; the real and imaginary parts of $A$ are denoted by $\operatorname{Re} A$ and $\operatorname{Im} A$ respectively:

$$
\operatorname{Re} A=\frac{A+A^{*}}{2}, \quad \operatorname{Im} A=\frac{A-A^{*}}{2 i} .
$$


For two Hermitian operators $A, B$ on $\mathscr{H}$, we write $A \geq B$ to indicate that $A-B$ is a positive operator, i.e., $\langle(A-B) x, x\rangle \geq 0$ for all $x \in \mathscr{H}$. The strict inequality $A>B$ means that $A-B$ is positive and invertible. The classical theorem stated above can be generalized to the following result.

THEOREM. Let $F$ be an operator-valued analytic function on the open half-plane $\Pi$ such that for each $z \in \Pi, F(z)$ is an operator on $\mathscr{H}$ with $\operatorname{Re} F(z)>0$. Suppose there is a Hermitian operator $A$ on $\mathscr{H}$ satisfying

$$
\frac{\operatorname{Re} F(z)}{\operatorname{Re} z}>A \quad \text { for all } z \in \Pi
$$

and

$$
\begin{aligned}
& \text { for any } \varepsilon>0 \text {, there is } z_{0} \in \Pi \text { such that } \\
& \qquad \frac{\operatorname{Re} F\left(z_{0}\right)}{\operatorname{Re} z_{0}}-A \|<\varepsilon .
\end{aligned}
$$

Then for any $k>0$ we have

$$
\begin{aligned}
\lim _{\substack{z \rightarrow \Sigma_{k} \\
z \in \Sigma_{k}}}\left\|\frac{F(z)}{z}-A\right\| & =\lim _{\substack{z \rightarrow \infty \\
z \in \Sigma_{k}}}\left\|\frac{\operatorname{Re} F(z)}{\operatorname{Re} z}-A\right\| \\
& =\lim _{\substack{z \rightarrow \infty \\
z \in \Sigma_{k}}}\left\|F^{\prime}(z)-A\right\|=0 .
\end{aligned}
$$

3. In proving our theorem, we shall need the following lemmas.

LEMMA 1. Let $F$ be an analytic function on $\Pi$ such that for each $z \in \Pi$, $F(z)$ is an operator on $\mathscr{H}$ with $\operatorname{Re} F(z)>0$. If $z, z_{0} \in \Pi$ and

$$
\begin{aligned}
\Psi\left(F(z), F\left(z_{0}\right)\right)= & {\left[\operatorname{Re} F\left(z_{0}\right)\right]^{-1 / 2}\left[F(z)-F\left(z_{0}\right)\right] } \\
& \times\left[F(z)+F\left(z_{0}\right)^{*}\right]^{-1}\left[\operatorname{Re} F\left(z_{0}\right)\right]^{1 / 2},
\end{aligned}
$$

then

$$
\Psi\left(F(z), F\left(z_{0}\right)\right)^{*} \Psi\left(F(z), F\left(z_{0}\right)\right) \leq\left|\frac{z-z_{0}}{z+\bar{z}_{0}}\right|^{2} I .
$$

Proof. This is part (d) of Theorem 3 in [1]. 
LEMMA 2. Let $F$ be an analytic function on $\Pi$ such that for each $z \in \Pi$, $F(z)$ is an operator on $\mathscr{H}$ with $\operatorname{Re} F(z)>0$. If $F\left(z_{0}\right)=I$ for some $z_{0} \in \Pi$, then

$$
\|F(z)\| \leq \frac{\left(|z|+\left|z_{0}\right|\right)^{2}}{(\operatorname{Re} z)\left(\operatorname{Re} z_{0}\right)} \quad \text { for } z \dot{\epsilon} \Pi
$$

Proof. According to the definition (8) of $\Psi$, we have

$$
\Psi(F(z), I)=[F(z)-I][F(z)+I]^{-1} ;
$$

so (9) becomes

(11) $\left[F(z)^{*}+I\right]^{-1}\left[F(z)^{*}-I\right][F(z)-I][F(z)+I]^{-1} \leq\left|\frac{z-z_{0}}{z+\bar{z}_{0}}\right|^{2} I$, for $z \in \Pi$.

Let

$$
\alpha(z)=\left|\frac{z-z_{0}}{z+\bar{z}_{0}}\right|^{2}
$$

which is clearly $<1$ for $z \in \Pi$. From (11) we have for $z \in \Pi$ :

$$
\left[F(z)^{*}-I\right][F(z)-I] \leq \alpha(z)\left[F(z)^{*}+I\right][F(z)+I],
$$

which can be written

$$
\left[F(z)^{*}-\frac{1+\alpha(z)}{1-\alpha(z)} I\right]\left[F(z)-\frac{1+\alpha(z)}{1-\alpha(z)} I\right] \leq \frac{4 \alpha(z)}{[1-\alpha(z)]^{2}} I
$$

or

$$
\left\|F(z)-\frac{1+\alpha(z)}{1-\alpha(z)} I\right\| \leq \frac{2 \alpha(z)^{1 / 2}}{1-\alpha(z)} .
$$

Then (10) follows from

$$
\begin{aligned}
\|F(z)\| & \leq\left\|F(z)-\frac{1+\alpha(z)}{1-\alpha(z)} I\right\|+\frac{1+\alpha(z)}{1-\alpha(z)} \\
& \leq \frac{2 \alpha(z)^{1 / 2}}{1-\alpha(z)}+\frac{1+\alpha(z)}{1-\alpha(z)} \\
& =\frac{\left(\left|z+\bar{z}_{0}\right|+\left|z-z_{0}\right|\right)^{2}}{4(\operatorname{Re} z)\left(\operatorname{Re} z_{0}\right)} \leq \frac{\left(|z|+\left|z_{0}\right|\right)^{2}}{(\operatorname{Re} z)\left(\operatorname{Re} z_{0}\right)} \quad \text { for } z \in \Pi .
\end{aligned}
$$


4. Proof of the theorem. With the aid of Lemma 2, the proof of our theorem is an operator-analogue of Landau-Valiron's proof [4], [5, pp. 87-89] of the classical case. Consider a fixed $\varepsilon>0$. By hypothesis, we can choose $z_{0} \in \Pi$ such that

$$
\left\|\frac{\operatorname{Re} F\left(z_{0}\right)}{\operatorname{Re} z_{0}}-A\right\|<\varepsilon
$$

Define operator-valued analytic functions $E$ and $G$ on $\Pi$ by

$$
E(z)=F(z)-A z,
$$

$$
G(z)=\left[\operatorname{Re} E\left(z_{0}\right)\right]^{-1 / 2}\left[E(z)-i \operatorname{Im} E\left(z_{0}\right)\right]\left[\operatorname{Re} E\left(z_{0}\right)\right]^{-1 / 2} .
$$

By (5), $\operatorname{Re} E(z)>0$ for $z \in \Pi$. As

$$
\operatorname{Re} G(z)=\left[\operatorname{Re} E\left(z_{0}\right)\right]^{-1 / 2}[\operatorname{Re} E(z)]\left[\operatorname{Re} E\left(z_{0}\right)\right]^{-1 / 2},
$$

we have also $\operatorname{Re} G(z)>0$ for $z \in \Pi$. Clearly $G\left(z_{0}\right)=I$. An application of Lemma 2 to $G$ gives

$$
\|G(z)\| \leq \frac{\left(|z|+\left|z_{0}\right|\right)^{2}}{(\operatorname{Re} z)\left(\operatorname{Re} z_{0}\right)} \quad \text { for } z \in \Pi .
$$

By (13), (14) and (16), we have for $z \in \Pi$ :

$$
\begin{aligned}
\left\|\frac{F(z)}{z}-A\right\| & =\frac{\|E(z)\|}{|z|} \\
& =\frac{1}{|z|}\left\|\left[\operatorname{Re} E\left(z_{0}\right)\right]^{1 / 2} G(z)\left[\operatorname{Re} E\left(z_{0}\right)\right]^{1 / 2}+i \operatorname{Im} E\left(z_{0}\right)\right\| \\
& \leq \frac{1}{|z|}\left\|\left[\operatorname{Re} E\left(z_{0}\right)\right]^{1 / 2}\right\|^{2}\|G(z)\|+\frac{\left\|\operatorname{Im} E\left(z_{0}\right)\right\|}{|z|} \\
& \leq \frac{\left\|\left[\operatorname{Re} E\left(z_{0}\right)\right]^{1 / 2}\right\|^{2}}{\operatorname{Re} z_{0}} \frac{\left(|z|+\left|z_{0}\right|\right)^{2}}{|z|(\operatorname{Re} z)}+\frac{\left\|\operatorname{Im} E\left(z_{0}\right)\right\|}{|z|} .
\end{aligned}
$$

Since

$$
\frac{\left\|\left[\operatorname{Re} E\left(z_{0}\right)\right]^{1 / 2}\right\|^{2}}{\operatorname{Re} z_{0}}=\frac{\left\|\operatorname{Re} E\left(z_{0}\right)\right\|}{\operatorname{Re} z_{0}}=\left\|\frac{\operatorname{Re} F\left(z_{0}\right)}{\operatorname{Re} z_{0}}-A\right\|<\varepsilon,
$$

it follows that

$$
\left\|\frac{F(z)}{z}-A\right\| \leq \varepsilon \frac{\left(|z|+\left|z_{0}\right|\right)^{2}}{|z|(\operatorname{Re} z)}+\frac{\left\|\operatorname{Im} E\left(z_{0}\right)\right\|}{|z|} \text { for } z \in \Pi .
$$


For $z \in \Sigma_{k}$ we have

$$
\begin{aligned}
\frac{\left(|z|+\left|z_{0}\right|\right)^{2}}{|z|(\operatorname{Re} z)} & =\left(1+\left|\frac{z_{0}}{z}\right|\right) \frac{|z|+\left|z_{0}\right|}{\operatorname{Re} z} \\
& \leq\left(1+\left|\frac{z_{0}}{z}\right|\right)\left(\sqrt{1+k^{2}}+\frac{\left|z_{0}\right|}{\operatorname{Re} z}\right) .
\end{aligned}
$$

Therefore

$$
\left\|\frac{F(z)}{z}-A\right\| \leq \varepsilon\left(1+\left|\frac{z_{0}}{z}\right|\right)\left(\sqrt{1+k^{2}}+\frac{\left|z_{0}\right|}{\operatorname{Re} z}\right)+\frac{\left\|\operatorname{Im} E\left(z_{0}\right)\right\|}{|z|}
$$

holds for $z \in \Sigma_{k}$. The right-hand side of (18) tends to $\varepsilon \sqrt{1+k^{2}}$ as $z \in \Sigma_{k}$ tends to $\infty$. Since $\varepsilon>0$ can be arbitrarily small, this proves that

$$
\lim _{\substack{z \rightarrow \sum_{k}^{\infty} \\ z \in \sum_{k}}}\left\|\frac{F(z)}{z}-A\right\|=0 .
$$

Next, by (13) we have

$$
\begin{aligned}
\left\|\frac{\operatorname{Re} F(z)}{\operatorname{Re} z}-A\right\| & =\left\|\frac{\operatorname{Re} E(z)}{\operatorname{Re} z}\right\| \leq \frac{\|E(z)\|}{\operatorname{Re} z} \\
& =\frac{|z|}{\operatorname{Re} z}\left\|\frac{F(z)}{z}-A\right\| \quad \text { for } z \in \Pi
\end{aligned}
$$

and therefore

(20)

$$
\left\|\frac{\operatorname{Re} F(z)}{\operatorname{Re} z}-A\right\| \leq \sqrt{1+k^{2}}\left\|\frac{F(z)}{z}-A\right\| \quad \text { for } z \in \Sigma_{k} .
$$

From (19) and (20), it follows that

$$
\lim _{\substack{z \in \Sigma_{k}^{\infty} \\ z \rightarrow \Sigma_{k}}}\left\|\frac{\operatorname{Re} F(z)}{\operatorname{Re} z}-A\right\|=0 .
$$

Given $k>0$, choose $h>0$ so small that for every $z \in \Sigma_{k}$ the circle $C_{h}(z)=\{w \in \mathbf{C}:|w-z|=h|z|\}$ is contained in $\Pi$. Then from Cauchy's integral formula $[3$, p. 96]

$$
E^{\prime}(z)=\frac{1}{2 \pi i} \int_{C_{h}(z)} \frac{E(w) d w}{(w-z)^{2}} \quad \text { for } z \in \Sigma_{k},
$$

we derive

$$
\begin{aligned}
\left\|E^{\prime}(z)\right\| & \leq \frac{1}{h|z|} \operatorname{Max}_{w \in C_{h}(z)}\|E(w)\|=\frac{1}{h} \operatorname{Max}_{w \in C_{h}(z)}\left|\frac{w}{z}\right|\left\|\frac{F(w)}{w}-A\right\| \\
& \leq \frac{1+h}{h} \operatorname{Max}_{w \in C_{h}(z)}\left\|\frac{F(w)}{w}-A\right\| \quad \text { for } z \in \Sigma_{k} .
\end{aligned}
$$


This together with (19) implies

$$
\lim _{\substack{z \rightarrow \infty \\ z \in \Sigma_{k}}}\left\|F^{\prime}(z)-A\right\|=\lim _{\substack{z \rightarrow \infty \\ z \in \Sigma_{k}}}\left\|E^{\prime}(z)\right\|=0 .
$$

The proof is complete.

\section{REFERENCES}

[1] T. Ando and K. Fan, Pick-Julia theorems for operators, Math. Z., 168 (1979), 23-34.

[2] R. B. Burckel, An Introduction to Classical Complex Analysis, Volume 1, Academic Press, New York-San Francisco, 1979.

[3] E. Hille and R. S. Phillips, Functional analysis and semigroups (Revised edition), Amer. Math. Soc. Colloq. Publ. 31, Amer. Math. Soc., Providence, 1957.

[4] E. Landau and G. Valiron, A deduction from Schwarz's lemma, J. London Math. Soc., 4 (1929), 162-163.

[5] G. Valiron, Fonctions analytiques, Presses Univ. de France, Paris, 1954.

Received July 24, 1984. Work supported in part by the National Science Foundation Grant MCS-8201544.

UNIVERSITY OF CALIFORNIA

SANTA Barbara, CA 93106 


\section{PACIFIC JOURNAL OF MATHEMATICS EDITORS}

V. S. VARADARAJAN (Managing Editor)
University of California
Los Angeles, CA 90024
HEBERT CLEMENS
University of Utah
Salt Lake City, UT 84112
CHARLES R. DEPRIMA
California Institute of Technology
Pasadena, CA 91125

\section{R. FINN}

Stanford University

Stanford, CA 94305

HeRmanN FlaschKa

University of Arizona

Tucson, AZ 85721

RAMESH A. GANGOLli

University of Washington

Seattle, WA 98195

ROBION KIRBY

University of California

Berkeley, CA 94720

\section{C. MoOre}

University of California

Berkeley, CA 94720

H. SAMELSON

Stanford University

Stanford, CA 94305

HAROLD STARK

University of California, San Diego

La Jolla, CA 92093

ASSOCIATE EDITORS
R. ARENS
E. F. BECKENBACH
B. H. NeUmanN
F. WOLF
K. Yoshida (1906-1982)

\section{SUPPORTING INSTITUTIONS}

UNIVERSITY OF ARIZONA

UNIVERSITY OF BRITISH COLUMBIA

CALIFORNIA INSTITUTE OF TECHNOLOGY

UNIVERSITY OF CALIFORNIA

MONTANA STATE UNIVERSITY

UNIVERSITY OF NEVADA, RENO

NEW MEXICO STATE UNIVERSITY

OREGON STATE UNIVERSITY
UNIVERSITY OF OREGON

UNIVERSITY OF SOUTHERN CALIFORNIA

STANFORD UNIVERSITY

UNIVERSITY OF HAWAII

UNIVERSITY OF TOKYO

UNIVERSITY OF UTAH

WASHINGTON STATE UNIVERSITY

UNIVERSITY OF WASHINGTON 


\section{Pacific Journal of Mathematics}

\section{Vol. 121, No. $1 \quad$ November, 1986}

Om P. Agrawal, Douglas Napier Clark and Ronald George Douglas,

Invariant subspaces in the polydisk $\ldots \ldots \ldots \ldots \ldots \ldots \ldots \ldots \ldots \ldots$

Christoph Bandt and Gebreselassie Baraki, Metrically invariant measures

on locally homogeneous spaces and hyperspaces $\ldots \ldots \ldots \ldots \ldots \ldots \ldots$

Marcy Mason Barge, Horseshoe maps and inverse limits ..............29

Russell Gene Bilyeu, Robert Richard Kallman and Paul Weldon Lewis,

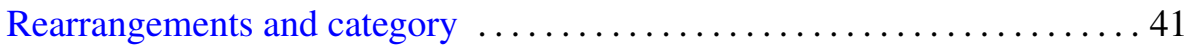

Jean Bourgain, A problem of Douglas and Rudin on factorization . . .......47

Hernan Cendra, A normal form and integration in finite terms for a class of

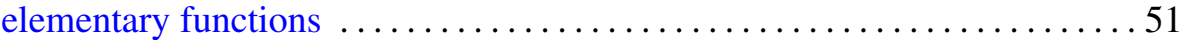

Ky Fan, The angular derivative of an operator-valued analytic function . . . . 67

Gerhard Gierz, On the Dunford-Pettis property of function modules of

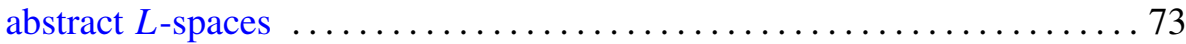

Gabriel Katz, On polynomial generators in the algebra of complex functions

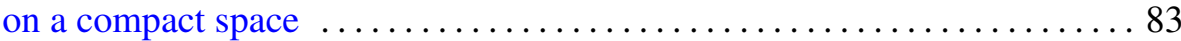

Ridgley Lange, Duality and asymptotic spectral decompositions $\ldots \ldots \ldots . .93$

Anthony To-Ming Lau and Peter F. Mah, Quasinormal structures for certain spaces of operators on a Hilbert space ................... 109

R. Daniel Mauldin, Correction: "The set of continuous nowhere differentiable functions"

Alan Harvey Mekler and Saharon Shelah, $\omega$-elongations and Crawley's problem

Alan Harvey Mekler and Saharon Shelah, The solution to Crawley's problem

Richard Rochberg, Deformation of uniform algebras on Riemann surfaces

Joseph Roitberg, On weak epimorphisms in homotopy theory

Jesús M. Ruiz, A remark on fields with the dense orbits property

Henry Wente, Counterexample to a conjecture of H. Hopf

David G. Wright, Rigid sets in $E^{n}$ 